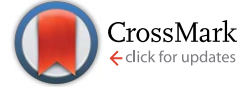

Cite this: J. Mater. Chem. A, 2015, 3 , 5072

Received 16th January 2015

Accepted 23rd January 2015

DOI: $10.1039 / c 5 t a 00369 e$

www.rsc.org/MaterialsA

\section{Photochemical and electrocatalytic water oxidation activity of cobalt carbodiimide $\uparrow$}

\author{
Debora Ressnig, ${ }^{\text {*a }}$ Menny Shalom, ${ }^{\text {a Jörg Patscheider, }}{ }^{\mathrm{c}}$ René Moré, ${ }^{\mathrm{b}}$ Fabio Evangelisti, ${ }^{\mathrm{b}}$ \\ Markus Antonietti ${ }^{a}$ and Greta R. Patzke*b
}

Cobalt carbodiimide is introduced as a heterogeneous non-oxidic water oxidation catalyst prototype with dual photochemical and electrocatalytic activity in neutral and basic media. CoNCN exhibits higher initial turnover frequencies of (TOF/S $\mathrm{BET}$ : $2.1 \times 10^{-1}$ ) for visible-light-driven oxygen evolution than cobalt oxide catalysts (TOF/S $S_{\mathrm{BET}}: 3.5 \times 10^{-3}$ ) and a $18 \%$ higher oxygen yield (Ru-dye sensitized standard setup). Furthermore, CoNCN maintains stable current densities in electrolysis over $20 \mathrm{~h}$, and structural tuning through cationic substitution revealed that mixed (Co, Ni)NCN catalysts with low Ni contents display higher current densities than pristine CoNCN. A wide range of bulk (XAFS/EXAFS, XRD, FTIR) and surface (XPS, EELS, HRTEM) analytical methods together with catalytic parameter variations and reference experiments were performed to confirm the stability of CoNCN under standard operational conditions. The carbodiimide matrix thus offers a straightforward structural alternative to oxide systems and a clearcut starting point for optimization strategies and for mechanistic studies on the possible role of active carbon or nitrogen sites. This paves the way to metal carbodiimides as a novel catalyst design platform for heterogeneous energy conversion systems.

\section{Introduction}

Artificial photosynthesis as a clean, bio-inspired and sustainable route to solar fuels depends on the development of stable and efficient water oxidation catalysts (WOCs). Economic heterogeneous catalysts are essential for the direct conversion of solar energy via water splitting. ${ }^{1-7}$ Even after decades of research into the complex four-electron-transfer processes of water oxidation, WOC development remains a major, general challenge. ${ }^{8-12}$ Manifold mechanistic studies have been performed on molecular WOCs with bio-inspired reaction pathways along the lines of nature's OEC of photosystem II. ${ }^{\mathbf{1 3 , 1 4}}$ In comparison, understanding the interfaces, active species and mechanisms associated with most heterogeneous colloidal water oxidation catalysts remains far more demanding, ${ }^{15}$ because pioneering surface spectroscopic techniques ${ }^{\mathbf{1 6}-18}$ and operando monitoring approaches ${ }^{\mathbf{1 9 - 2 2}}$ are required. However, detailed mechanistic insight as well as structure-activity relationships for a wide spectrum of materials are indispensable for

${ }^{a}$ Max Planck Institute of Colloids and Interfaces, Am Mühlenberg 1, D-14476 Potsdam, Germany.E-mail: debora.ressnig@mpikg.mpg.de

${ }^{b}$ Department of Chemistry, University of Zurich, Winterthurerstrasse 190, CH-8057 Zurich, Switzerland. E-mail: greta.patzke@aci.uzh.ch

${ }^{c}$ Laboratory for Nanoscale Materials Science, EMPA Dübendorf, CH-8600 Dübendorf, Switzerland

$†$ Electronic supplementary information (ESI) available: Material characterizations and addition photo- and electrocatalytic data are available. See DOI: 10.1039/c5ta00369e informed WOC construction. This calls for new structurally clear-cut model systems which facilitate the investigation of catalytic stability and active species.

We therefore introduce cobalt carbodiimide (CoNCN) as a new prototype for the investigation of three key WOC design issues. First, we report on the dual photochemical and electrocatalytic activity of CoNCN. Second, we explore the challenging question of the "true catalyst" for cobalt centers in an all-nitrogen/carbon environment. Third, we present clear-cut transition metal tuning options for the robust carbodiimide catalyst matrix.

Traditionally, artificial photosynthesis research has placed special emphasis on oxide-based materials, such as spinel- and perovskite-type WOCs, ${ }^{23}$ oxynitrides, ${ }^{16,17}$ powerful electrodeposited catalysts $^{20}$ and PSII-inspired molecular WOCs. $^{24}$ Whereas molecular WOCs provide valuable insight to into reaction mechanisms, they are also likely to undergo transformations under operational conditions. ${ }^{25}$ Heterogeneous WOCs are more robust, but they display a complex interdependence of composition, structure, morphology/surface area, oxidation states and preparative history.,26 The stability of each WOC type and its possible in situ transformation gives rise to substantial discussions about the true active species. As a consequence, key performance parameters are quite difficult to assign,$^{27}$ which also renders precise extrapolation of photo- on electrocatalytic activity and vice versa rather difficult. ${ }^{28}$

Efficient and economic cobalt-containing catalysts perfectly illustrate these complex challenges, given that they currently 
attract increasing research interest among the multitude of WOC types. ${ }^{29-31}$ Cluster-based Co-WOCs have launched an ongoing debate about in situ transformations into active oxide species. $^{32,33}$ On the other hand, in-depth post-catalytic studies on heterogeneous cobalt-containing electrocatalysts, e.g. $\mathrm{Co}\left(\mathrm{PO}_{3}\right)_{2}$ (ref. 34) and Co-perovskites, ${ }^{23}$ outlined the productive aspects of restructuring effects. $\mathrm{Co}_{3} \mathrm{O}_{4}$ materials are leading heterogeneous catalysts due to their flexible application in either dye sensitized or electrochemical systems. ${ }^{35,36}$ Only recently first light has been shed on their intermediates under operational water oxidation conditions. ${ }^{37} \mathrm{CoO}_{x}$ materials are furthermore applied as exceptional electrocatalysts or as cocatalysts in photocatalytic conversions with high efficiency in neutral media. ${ }^{38}$ They are typically electrodeposited from various buffer solutions (e.g. phosphate buffer $\mathrm{CoP}_{\mathrm{i}}$ ) onto electrodes or semiconductor substrates. Latest results underscore the importance of technical processing factors for their performance, such as electrode microstructure and layer thickness, along with innovative approaches for the preparation of mixed amorphous catalysts. ${ }^{39,40}$ Nevertheless, the mechanisms and local structures of amorphous cobalt oxide-based catalysts keep giving rise to multidisciplinary studies depicting the complexity associated with structure-activity relationships of these materials. ${ }^{20,30,41-45}$ Studies on the oxidative decomposition of labile molecular Co-WOCs to $\mathrm{CoO}_{x}$ species highlight the crucial role of intercalated carbonaceous materials in tuning the catalytic activity. ${ }^{29}$

This renders alternative WOC types with less variable and demanding structural motifs highly desirable to expand the spectrum of tuning and mechanistic studies. Over the past years, non-oxide WOCs have attracted increasing research attention. $^{46,47}$ Amongst them, nitrogen and carbon based materials emerge as low-cost and efficient oxide- and metal-free photo- and electrocatalysts with a wide application spectrum including OER, HER, ORR and $\mathrm{CO}_{2}$ reduction processes. ${ }^{48-55}$ Their mechanistic functionality models involve nitrogen moieties, defects and, most interestingly, positively polarized carbons as active sites. Metal doping or deposition of co-catalysts emerge as the most recent strategies to modify the performance of such materials through synergistic effects. ${ }^{56-59}$ Moreover, silver cyanamide has shown promising activity as semiconductor photoanode, ${ }^{60}$ albeit with the pending issue of typically limited photostability of Ag-based catalysts. Most recently, Prussian Blue-type electrocatalysts have been reported as an exceptionally stable alternative to cobalt oxide catalysts. ${ }^{61,62}$ This combination of non-oxide matrices with catalytically active cobalt centers still leaves plenty of room for discoveries. ${ }^{63-65}$ and inspired us to further tap into the widely unexplored potential of early transition metal WOCs with nitrogen-based matrices.

We selected CoNCN as an innovative target material with $\left\{\mathrm{CoN}_{6}\right\}$ moieties embedded into a NiAs-related matrix. These moieties not only resemble structural units in amorphous $\mathrm{CoO}_{x}$ materials but also complement most hitherto known oxide catalyst structure types in highly crystalline form (Fig. 1). In the following, we compare the photo- and electrocatalytic performance of CoNCN. Furthermore, we present coherent trends for
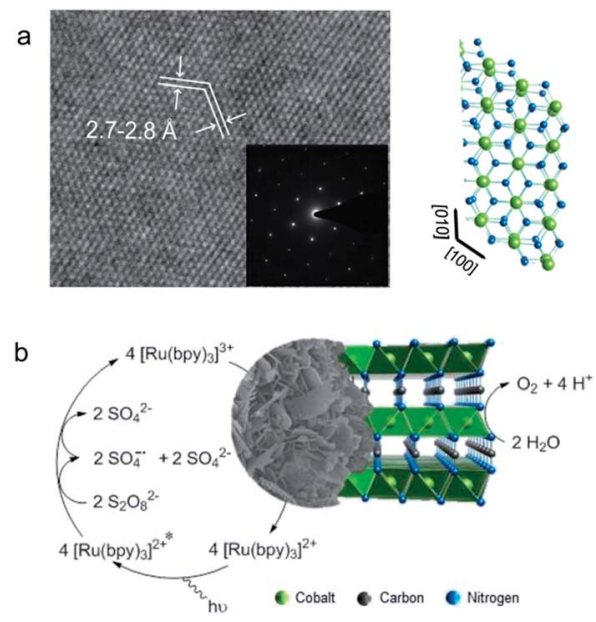

Fig. 1 (a) HRTEM and SAED pattern of a CONCN platelet along with the structural motif. (b) Photocatalytic water oxidation cycle with cobalt carbodiimide.

the operational stability of the new dual WOC. Finally, we demonstrate that CoNCN electrocatalysts display high optimization potential through $\mathrm{Ni}$ doping.

\section{Results and discussion}

\section{Synthetic route and characterization}

CoNCN was synthesized via a modified hydrogencyanamide route through dissolution of $\mathrm{CoCl}_{2}$ in molten cyanamide at $75{ }^{\circ} \mathrm{C}$, followed by addition of ammonium carbonate and decomposition/recrystallization in a $\mathrm{LiCl} / \mathrm{KCl}$ salt melt at $400{ }^{\circ} \mathrm{C} .{ }^{66}$ The advantages of this synthetic protocol include fast precipitation of the precursor, which is favorable for the formation of small particles, and facile scale-up to gram quantities ( $c f$. ESI $\dagger$ for experimental details). Characterization of CoNCN with a wide range of analytical techniques ((HR)TEM, SEM/EDX, PXRD, UV/vis \& FT-IR spectroscopy, BET, elemental analyses) verifies the formation of phase pure CoNCN platelets

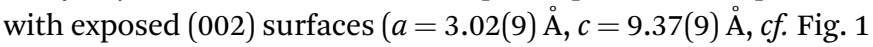
and S1-S4, Table S1†).

\section{Photochemical water oxidation with CoNCN}

Performance parameters of CoNCN. The visible-light-driven water oxidation activity of CoNCN was evaluated with standard protocols utilizing $\left[\mathrm{Ru}(\mathrm{bpy})_{3}\right]^{2+}$ as photosensitizer (PS) and $\mathrm{S}_{2} \mathrm{O}_{8}{ }^{2-}$ as electron acceptor (Fig. 1b, for experimental details $c f$. ESI $\dagger) .{ }^{67}$ Normalized turnover frequencies were approximated on the basis of BET surface areas (TOF/ $\left./ S_{\mathrm{BET}}\right)$. When comparing these values, it is essential to point out that the precise interaction steps between PS and various catalyst surfaces still remain to be fully explored. ${ }^{37}$ The UV/vis absorption spectrum of CoNCN (Fig. S3†) displays a low degree of diffuse self-absorption that does not significantly interfere with PS absorption in the visible range. As a further advantage, the oxygen-free structural motif of CoNCN renders ${ }^{18} \mathrm{O}$ labelling experiments obsolete. 
Standard conditions were defined after optimization runs in various buffer media as follows: $1.5 \mathrm{mM}$ CoNCN in phosphate or carbonate buffer with $1 \mathrm{mM}\left[\mathrm{Ru}(\mathrm{bpy})_{3}\right]^{2+}$ and $5 \mathrm{mM} \mathrm{Na} \mathrm{S}_{2} \mathrm{O}_{8}$ (Fig. 2 and Table S2 $\dagger$ ). Reference experiments in the absence of light, catalyst, PS or electron acceptor (Tables S2 and S3†) demonstrate that all components of the catalytic scheme are indispensable for oxygen evolution. No significant induction time was observed for oxygen evolution with the CoNCN-WOC under optimized conditions, whereas a slight delay was observed for catalyst concentrations of $2.5 \mathrm{mM}$ and above, which is likely due to concentration-related shielding, charge accumulation and other secondary effects. These results strongly suggest that CoNCN is the active WOC under optimized working conditions.

The WOC performance of CoNCN increases with the $\mathrm{pH}$ value, and a maximum oxygen yield of $75 \%\left(\mathrm{TOF} / S_{\mathrm{BET}}: 2.1 \times\right.$ $10^{-1}$ ) is obtained in a carbonate buffer at pH 9 (Fig. 2). Interestingly, this trend overcompensates the opposite effect of PS decomposition with increasing $\mathrm{pH}$ value. Mechanistic reasons for this behavior might include kinetic effects via a rate-determining step depending on $\left[\mathrm{HO}^{-}\right]$or enhanced PS adsorption through electrostatic surface phenomena. Buffer-dependent WOC performance was furthermore found to increase in the order carbonate $\approx$ phosphate $\gg$ borate, despite the higher stability of $\left[\mathrm{Ru}(\mathrm{bpy})_{3}\right]^{2+}$ in borate compared to phosphate media. ${ }^{68,69}$

Recycling tests with CoNCN. Catalyst recycling experiments at pH 9 upon addition of fresh carbonate buffer solution and PS/ electron acceptor, respectively, resulted in a reactivation of WOC performance by $c a$. $40 \%$ after the first run, followed by minor losses during subsequent cycles (Fig. S5†). Such reduced catalytic activity in the second cycle has also been observed for recovered spinel oxide WOCs. ${ }^{26,70}$ Given that the analytical investigations did not point to any major structural or stability/ leaching issues (as detailed below), surface deactivation processes, e.g. through PS decomposition, are most likely responsible for incomplete WOC reactivation.

Photochemical WOC performance of $\mathrm{CoNCN}$ vs. $\mathrm{Co}_{3} \mathrm{O}_{4}$. Next, CoNCN was compared to spinel-type $\mathrm{Co}_{3} \mathrm{O}_{4}$ as a crystalline, high performance oxide WOC standard. Recent studies demonstrated that the key prerequisites for high heterogeneous nanocatalyst activity in dye sensitized photocatalytic assays are not only morphology and surface area but also high crystallinity. ${ }^{70}$ Two representative $\mathrm{Co}_{3} \mathrm{O}_{4}$ references with different surface areas and morphologies were selected, namely hydrothermally synthesized $\mathrm{Co}_{3} \mathrm{O}_{4}$ nanoparticles ${ }^{70}$ and commercial powder samples consisting of polycrystalline microcrystals (Fig. S6-S8†).

CoNCN exhibits considerably higher normalized activity $\left(\mathrm{TOF} / S_{\mathrm{BET}}: 2.1 \times 10^{-1}\right)$ under standard conditions than both nanoscale $\left(\mathrm{TOF} / S_{\mathrm{BET}}: 3.5 \times 10^{-3}\right)$ and microscale $\mathrm{Co}_{3} \mathrm{O}_{4}(\mathrm{TOF} /$ $S_{\mathrm{BET}}: 4.4 \times 10^{-4} ; c f$. Table 1 and Fig. 2$)$. Most importantly, the lower surface area of CoNCN $\left(14 \mathrm{~m}^{2} \mathrm{~g}^{-1}\right)$ compared to the $\mathrm{Co}_{3} \mathrm{O}_{4}$ references (nanoparticles: $71 \mathrm{~m}^{2} \mathrm{~g}^{-1}$, commercial standard: $56 \mathrm{~m}^{2} \mathrm{~g}^{-1}$ ) suggests that the influence of the structural motif in combination with interface polarity effects outweighs any a

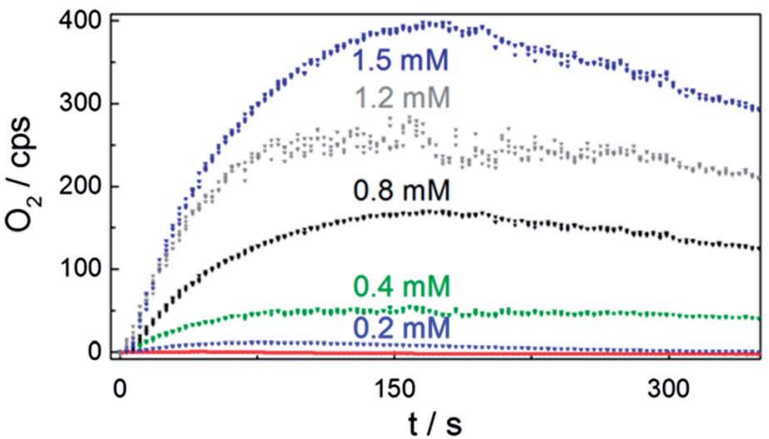

b

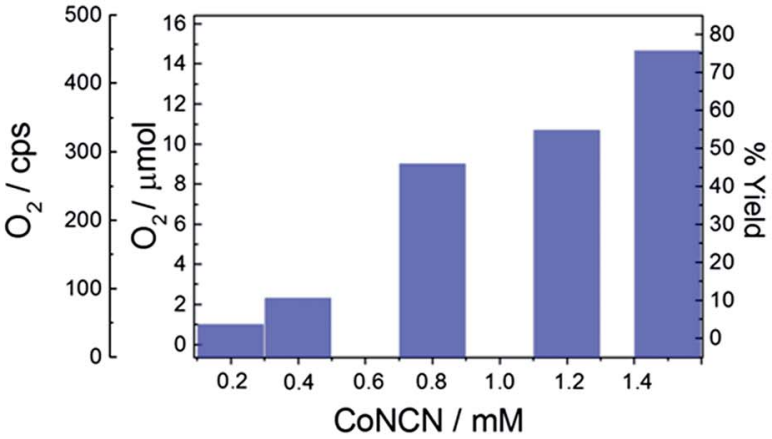

C

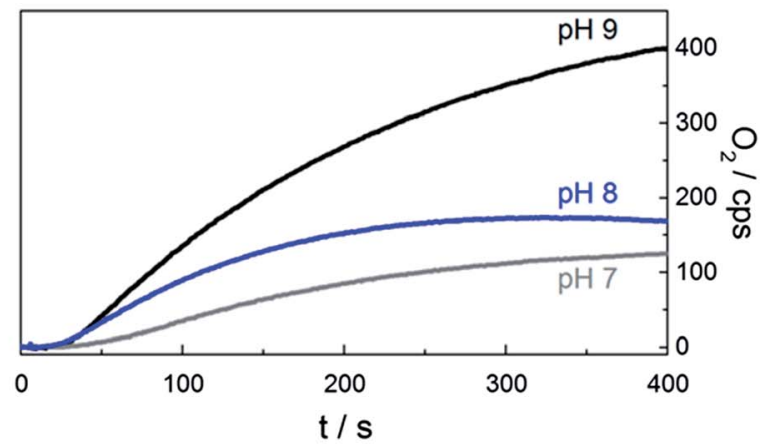

d

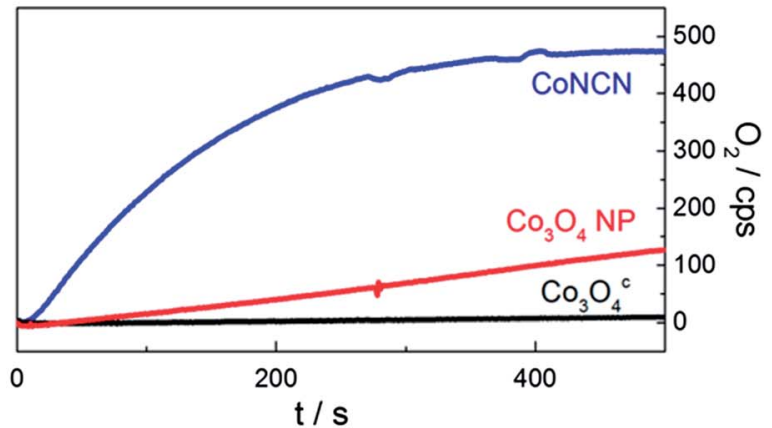

Fig. 2 (a) Clark-electrode kinetics of visible-light-driven $\mathrm{O}_{2}$ evolution for different concentrations of CoNCN, (b) corresponding water oxidation activity under standard photocatalytic conditions ( $470 \mathrm{~nm} \mathrm{LED;} 1 \mathrm{mM}\left[\mathrm{Ru}(\mathrm{bpy})_{3}\right] \mathrm{Cl}_{2}, 5 \mathrm{mM} \mathrm{Na} \mathrm{S}_{2} \mathrm{O}_{8}$, pH 9 (carbonate buffer)). (c) pH dependent visible-light-driven oxygen evolution activity of $\mathrm{CoNCN}$ in phosphate buffer at $\mathrm{pH} 7$ (grey), $\mathrm{pH} 8$ (blue) and pH 9 (black). (d) Oxygen evolution activity of $\mathrm{CoNCN}$ (blue) vs. $\mathrm{CO}_{3} \mathrm{O}_{4}$ nanoparticles (red) and commercially purchased $\mathrm{CO}_{3} \mathrm{O}_{4}{ }^{c}$ (black) in carbonate buffered solution at pH 9 (cf. Table 1). 
Table 1 Performance of CoNCN in photocatalysis compared to different $\mathrm{CO}_{3} \mathrm{O}_{4}$ WOCs ${ }^{a}$

\begin{tabular}{llll}
\hline Catalyst & $\begin{array}{l}S_{\mathrm{BET}} \\
{\left[\mathrm{m}^{2} \mathrm{~g}^{-1}\right]}\end{array}$ & $\begin{array}{l}\mathrm{O}_{2} \text { yield }^{b} \\
{[\%]}\end{array}$ & \begin{tabular}{l}
${\text { TOF } S_{\mathrm{BET}}{ }^{-1}}_{\left[\mathrm{g} \mathrm{s}^{-1} \mathrm{~m}^{-2}\right]}$ \\
\hline $\mathrm{CoNCN}$
\end{tabular} \\
$\mathrm{Co}_{3} \mathrm{O}_{4} \mathrm{NPS}$ & 14 & 76 & $2.1 \times 10^{-1}$ \\
$\mathrm{Co}_{3} \mathrm{O}_{4}{ }^{c}$ & 71 & 56 & $3.5 \times 10^{-3}$ \\
& 56 & 3 & $4.4 \times 10^{-4}$
\end{tabular}

${ }^{a}$ Standard conditions: $1.5 \mathrm{mM}$ WOC, $1 \mathrm{mM}\left[\mathrm{Ru}(\mathrm{bpy})_{3}\right]^{2+}, 5 \mathrm{mM} \mathrm{Na}_{2} \mathrm{~S}_{2} \mathrm{O}_{8}$, $470 \mathrm{~nm}$, carbonate buffer (pH 9). ${ }^{b} \mathrm{O}_{2}$ amount relative to initial $\mathrm{S}_{2} \mathrm{O}_{8}{ }^{2-}$ concentration $(2: 1) .{ }^{c}$ Commercially purchased material.

surface area related effects. This superior performance of CoNCN over $\mathrm{Co}_{3} \mathrm{O}_{4}$ as a benchmark oxide was further backed with stability tests as detailed in the following.

\section{CoNCN as a model system for catalytic stability studies}

Absence of secondary catalytic species under visible-lightdriven conditions. Formation of secondary WOC species through PS decomposition and CoNCN leaching was excluded with a series of control experiments and characterizations on the postcatalytic reaction solution. First, the supernatant post-catalytic solution was recovered by centrifugation, and dynamic light scattering (DLS) analyses did not display any nanoparticle formation above $1 \mathrm{~nm}$ in size (Fig. S9†). The presence of colloidal secondary WOCs was excluded through recycling experiments with both pristine and supernatant solutions. Neither solution displayed catalytic activity after addition of fresh $\mathrm{Na}_{2} \mathrm{~S}_{2} \mathrm{O}_{8}$ and PS upon $\mathrm{pH}$ readjustment (Fig. $\mathrm{S} 9 \dagger$ ). Additional control experiments to exclude $\mathrm{RuO}_{2}$ as a catalytically active species were performed by replacing CoNCN with according amounts of Ru-containing references $\left(\mathrm{RuO}_{2}\right.$ and $\left.\mathrm{RuCl}_{3} \cdot x \mathrm{H}_{2} \mathrm{O}\right)$. Ru contents were adjusted to simulate an overall degradation of the photosensitizer $(1 \mathrm{mM}$ $\left[\mathrm{Ru}(\mathrm{bpy})_{3}\right] \mathrm{Cl}_{2}$ ) into an equimolar amount of $\mathrm{RuO}_{2}(1 \mathrm{mM})$. Additionally, a lower extent (10\%) of PS decomposition was modeled using $0.1 \mathrm{mM} \mathrm{RuO}_{2}$. Parallel tests were performed replacing $\mathrm{RuO}_{2}$ with $\mathrm{RuCl}_{3} \cdot x \mathrm{H}_{2} \mathrm{O}$ under equivalent conditions (Fig. S10 $\dagger$ ). None of these experiments displayed oxygen evolution comparable to CoNCN, which strongly indicates that the activity under standard conditions does not arise from PS decomposition products. Cyanide determination tests with representative suspensions of CoNCN in the presence/absence of $\mathrm{Na}_{2} \mathrm{~S}_{2} \mathrm{O}_{8}$ were negative throughout, thus confirming stability of the new WOC type against cyanide leaching under operational conditions (Table S4 $\dagger$ ). Additional FT-IR tests of the supernatant solutions of aged pre- and postcatalytic suspensions furthermore confirm the absence of water-soluble $\mathrm{H}_{2-x} \mathrm{NCN}^{x-}$ and its hydrolysis products (Fig. S11 $\dagger$ ). Analytical cross-checks of pre- and postcatalytic solutions and catalyst thus indicate no degradation of CoNCN or formation of secondary Ru-oxide catalytic species on the experimental timescale.

Post-photocatalytic bulk stability of CoNCN. The structural integrity of CoNCN after photochemical water oxidation was investigated with a wide spectrum of complementary analytical techniques.
PXRD patterns of recovered CoNCN WOCs do not display notable differences from the pristine material nor any indications for the presence of crystalline cobalt oxide (Fig. S12 $\dagger$ ). Moreover, neither FT-IR, EDX nor EELS spectra indicated cobalt oxide formation during catalysis as evident from the absence of structural $\mathrm{O} / \mathrm{OH}$ signals (Fig. S13-S15 $\dagger$ ). Next, we examined post-catalytic CoNCN with complementary X-ray techniques including HRTEM and XAFS/XANES in combination with XPS for the potential formation of amorphous species. Both pristine and post-catalytic CoNCN display identical lattice fringes in HRTEM measurements that indicate the retention of a high degree of crystallinity in line with the PXRD results (Fig. S16 $\dagger$ ). The corresponding SAED patterns exclusively display clear diffraction spots from crystalline material without diffuse reflectance (Fig. S17†). All in all, no indications for amorphization, extensive atomic displacements or growth of another catalytic species on the surface of CoNCN during photo driven water oxidation were found.

Comparison of the XANES region for pristine CoNCN and for a sample aged in carbonate buffer shows no significant differences in the respective electronic and local geometric structures (see Fig. S18†), and only minor changes are visible for post-catalytic CoNCN (Fig. 3). The edge position for the post-catalytic sample is shifted by $1.1 \mathrm{eV}$ to higher energies relative to the pristine sample, which may be due to the formation of minor $\mathrm{Co}^{3+}$ amounts during the photocatalytic process. The cobalt valence states of the pristine and post-catalytic samples were determined as $1.95 \pm 0.02$ and $2.15 \pm 0.08$, respectively, using a calibration curve based on cobalt reference samples. The EXAFS regions for pristine and post-catalytic CoNCN were fitted against room temperature crystallographic data. ${ }^{7}$ EXAFS data fits for both

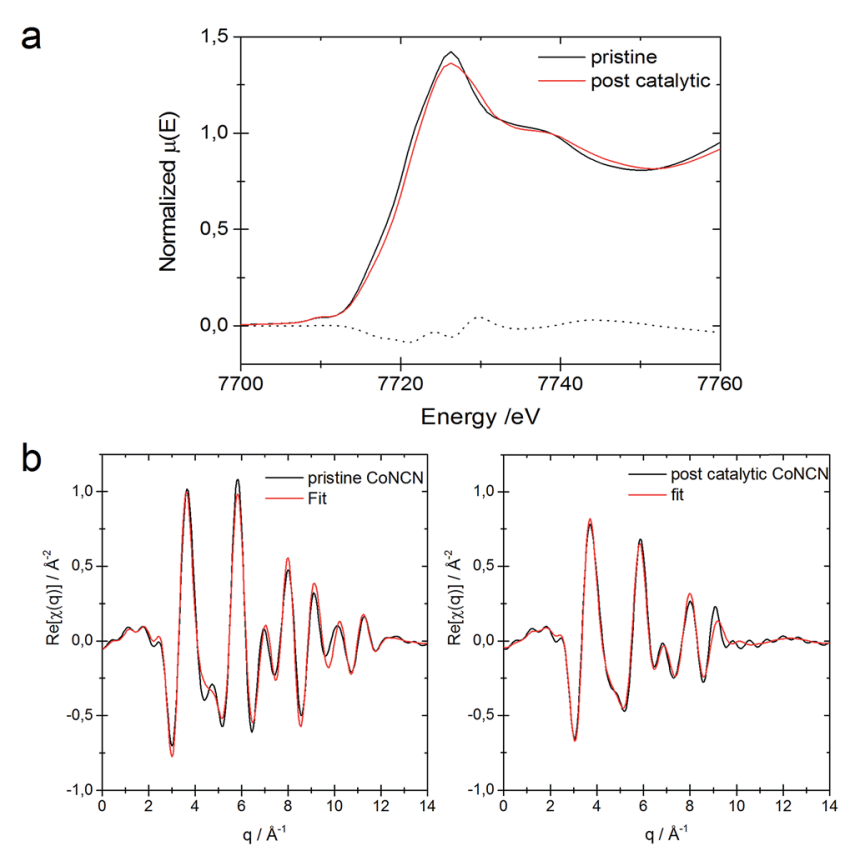

Fig. 3 (a) XANES region for pristine and post-catalytic CONCN and their difference spectrum. (b) EXAFS fit for pristine catalytic CoNCN vs. crystallographic data. ${ }^{66}$ 
samples are of good quality with $r$-factors of $1.7 \%$ and $1.9 \%$, respectively (Fig. 3 and Table S5†). The slight decrease of the interatomic distances for the post-catalytic sample is within the error ranges (Table $55 \dagger$ ) associated with an increase of the mean squared displacements with respect to the pristine sample. The interatomic distances for both pristine and post-catalytic samples could be fitted against the same structural model with a rather small difference of the interatomic distances $(<0.1 \AA)$, i.e. they are practically congruent with literature values for CoNCN. ${ }^{66}$ Furthermore, comparison of the edge positions for pristine and post-catalytic CoNCN reveal a rather negligible extent of oxidation under photocatalytic conditions.

In summary, XAFS analyses in their entirety show that CoNCN did not undergo any significant structural changes during photocatalysis.

Surface stability of CoNCN after photocatalysis. The absence of in situ formed oxide layers on the surface of CoNCN was demonstrated with XPS analyses on three representative CoNCN samples (pristine, aged in buffer and post-catalytic). Most importantly, the O1s XPS peaks of all three materials only consist of contributions from surface adsorbed oxygen species, while lattice oxygen species at energies lower than $530 \mathrm{eV}$ are absent (Fig. 4). ${ }^{71,72}$ This result clearly shows that no persistent oxide layers are formed at any stage of the catalytic cycle. Comparison of the Co2p XPS peaks for all CoNCN samples does not reveal significant differences between pre- and post-catalytic cobalt oxidation states, in line with the XANES results (see Fig. S19†).

Whereas the present set on CoNCN strongly suggests stability under operational photocatalytic conditions, the complete analysis of catalytic species and mechanisms remains a complex multidisciplinary problem that requires follow-up studies in their own right with highly specialized in situ analytical equipment. ${ }^{15,21,73}$

\section{Electrochemical water oxidation with CoNCN}

Electrocatalytic performance of CoNCN. To further elucidate the catalytic properties of CoNCN, we studied its

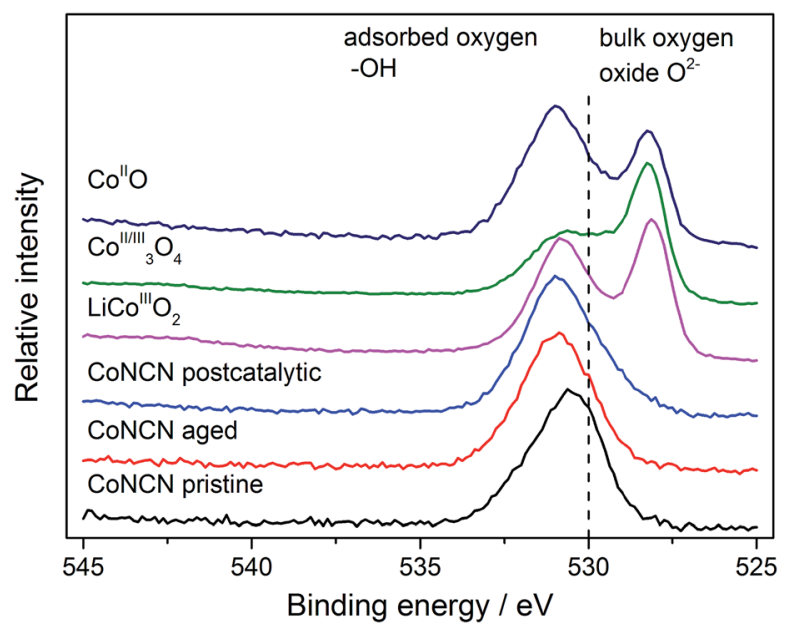

Fig. 4 XPS analysis of CoNCN O1s XPS peaks (pristine, aged in carbonate buffer and post-photocatalytic) vs. cobalt oxide references. electrochemical characteristics in a three electrode standard setup (Ag/AgCl reference, Pt counter and glassy carbon working electrode) in phosphate or $\mathrm{NaOH}$ buffered solution $(0.1 \mathrm{M})$ at pH 7 or 13, respectively. The linear sweep voltammetry (LSV) curve recorded in neutral solution shows a low resolved feature around $0.9 \mathrm{~V}$ prior to the onset of the catalytic wave at higher scan rates, arising from the $\mathrm{Co}^{\mathrm{II}} / \mathrm{Co}^{\mathrm{III}}$ and $\mathrm{Co}^{\mathrm{III}} / \mathrm{Co}^{\mathrm{IV}}$ redox couples (Fig. 5). The current density in the catalytic region is attributed to Faradaic currents only, as the measured capacitive currents were insignificant (Fig. S20†).

Catalytic current densities of $55 \mu \mathrm{A} \mathrm{cm} \mathrm{cm}^{-2}$ and $1 \mathrm{~mA} \mathrm{~cm} \mathrm{~cm}^{-2}$ were measured $320 \mathrm{mV}$ and $480 \mathrm{mV}$ above the thermodynamic potential of the OER $\left(E^{0}(\mathrm{pH} 7)=0.62 \mathrm{~V} v s\right.$. Ag/AgCl) in chronoamperometry measurements (Fig. $\mathrm{S} 21 \dagger$ ). The catalytic onset potential is therefore within the reported range for cobalt oxidebased electrocatalysts, such as $\mathrm{CoPi}(\eta=280 \mathrm{mV})$ or $\mathrm{Co}\left(\mathrm{PO}_{3}\right)_{2}$ $(\eta=310 \mathrm{mV})$ and $\mathrm{Co}_{3} \mathrm{O}_{4}(\eta=434 \mathrm{mV})$, respectively. ${ }^{34,72,74}$ However, the current density increase appears delayed as the Tafel slope accounts for around $122 \mathrm{mV} \mathrm{dec}^{-1}$ (Fig. 5). ${ }^{30}$

Bulk stability of CoNCN electrocatalysts. Furthermore, pristine CoNCN was deposited on FTO electrodes for long time measurements, and a stable current was recorded over several hours (Fig. 5). The absence of cobalt ions in the post-catalytic buffer solution was proven by ICP-OES analyses and indicates negligible Co-leaching levels during electrolysis. Additionally, the LSV curves recorded after 0,500 and 1000 cyclic voltammetry oxidation cycles differ only slightly with respect to catalytic onset potentials and slopes in the catalytic regions (Fig. S22 $\dagger$ ). Both techniques indicate stable performance of CoNCN as water electrolysis catalyst. Post-electrocatalytic electron microscopy, PXRD and FT-IR analyses (Fig. S23-S25 $\dagger$ ) corroborate the structural stability of bulk CoNCN.

Stability of CoNCN under electrocatalytic conditions was tested with XANES and EXAFS measurements on three postcatalytic FTO electrodes after $20 \mathrm{~h}$ of electrolysis in different buffer media (Fig. S26-S28†), namely sodium phosphate (NaPi, $\mathrm{pH} 7$ ), potassium phosphate (KPi, $\mathrm{pH} \mathrm{7}$ ) and $\mathrm{KOH}(\mathrm{pH} \mathrm{13).}$ XANES linear combination fits of the first derivatives of the normalized spectra were performed with $\mathrm{CoO}$ and $\mathrm{LiCoO}_{2}$ as references. The results revealed that all three materials contain $\mathrm{Co}^{3+}$ amounts in the range of 22-28\% after electrolysis (Fig. S27 and Table S6†). EXAFS fits against literature models ${ }^{66}$ for CoNCN displayed good agreements of experimental and structural data with $R$ values in the range of 1.5-2.7\% (Fig. 6 and Table $\mathrm{S} 7 \dagger$ ). Co-N and Co-C bond lengths agree with crystallographic data within the experimental error range, given that data were recorded in fluorescence mode with a rather small $k$ space. All in all, XAS data indicate overall robustness of the CoNCN under electrocatalytic conditions. However, slight surface modifications cannot be excluded with the present data set.

Therefore, FTO electrodes regenerated from NaPi and KPi solutions were investigated with Raman spectroscopy for the presence of secondary oxide phases (Fig. 7; FTO electrodes treated in $\mathrm{KOH}$ did not contain sufficient CoNCN amounts). Comparison of electrode Raman spectra with pristine CoNCN, $\mathrm{Co}_{3} \mathrm{O}_{4}$ and $\mathrm{CoO}$ references clearly show the absence of 

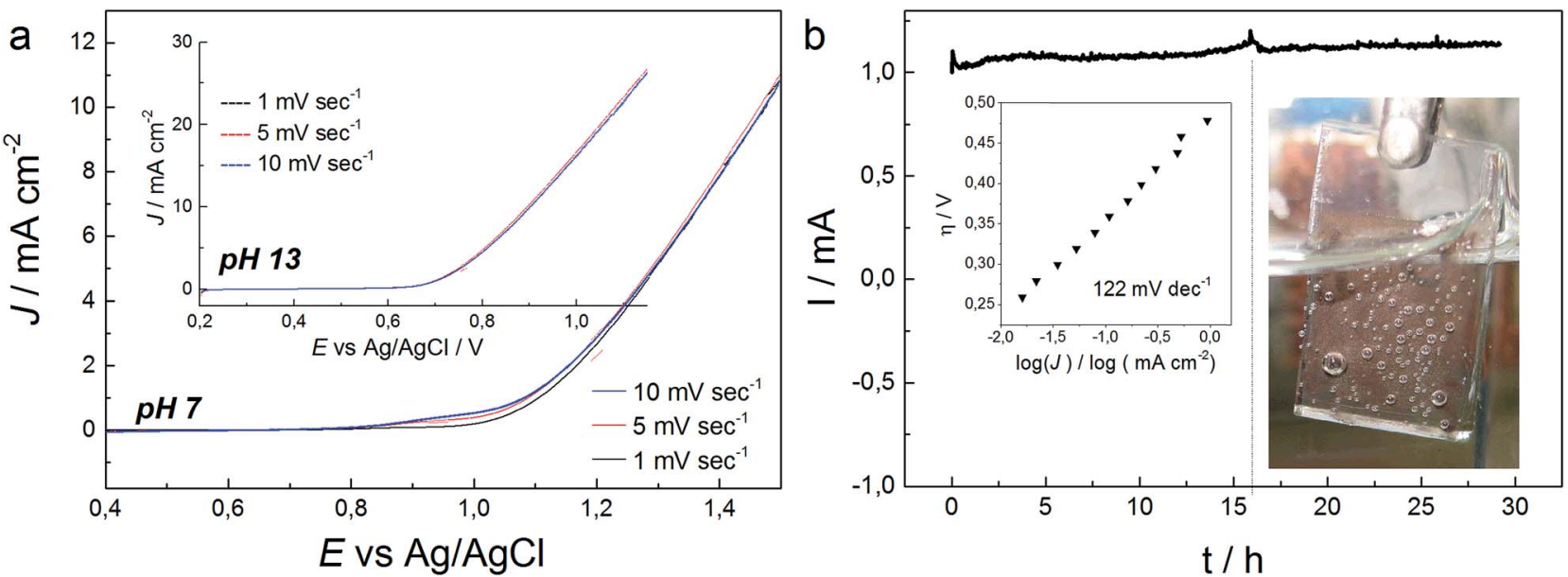

Fig. 5 (a) LSV curves of CoNCN, recorded at different scan rates in $0.1 \mathrm{M}$ phosphate buffer at a rotation speed of $1500 \mathrm{rpm}\left(E^{0}(\mathrm{pH} 7)=0.62 \mathrm{~V}\right.$ and $E^{\mathrm{O}}(\mathrm{pH} 13)=0.27 \mathrm{~V}$ vs Ag/AgCl). (b) Representative chronoamperometry measurement of CoNCN on a FTO electrode at $1.2 \mathrm{~V}$ vs. Ag/AgCl in $0.1 \mathrm{M}$ phosphate buffer $\left(E^{0}(\mathrm{pH} 7)=0.62 \mathrm{~V} v \mathrm{~s}\right.$. Ag/Ag/Cl). The dotted line indicates mechanical removal of bubbles. The inset shows the Tafel plot with a glassy carbon electrode under the same conditions.

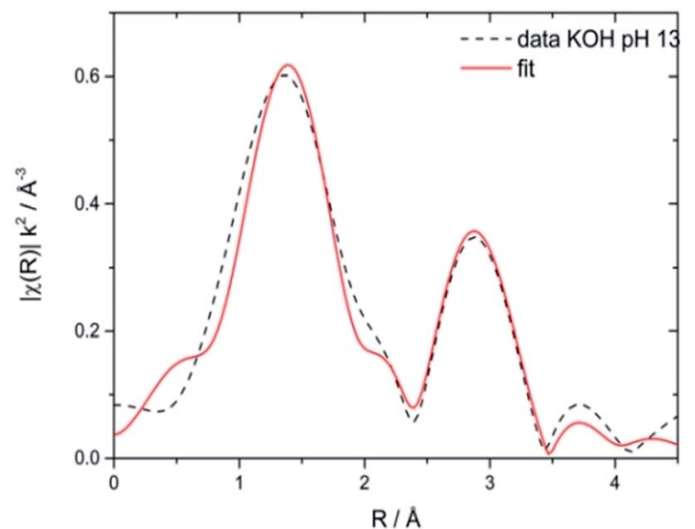

Fig. 6 Representative EXAFS spectrum of CONCN electrocatalyst on a FTO electrode after $20 \mathrm{~h}$ of electrolysis in $\mathrm{KOH}(\mathrm{pH}$ 13) fitted vs. structural reference data. ${ }^{66}$

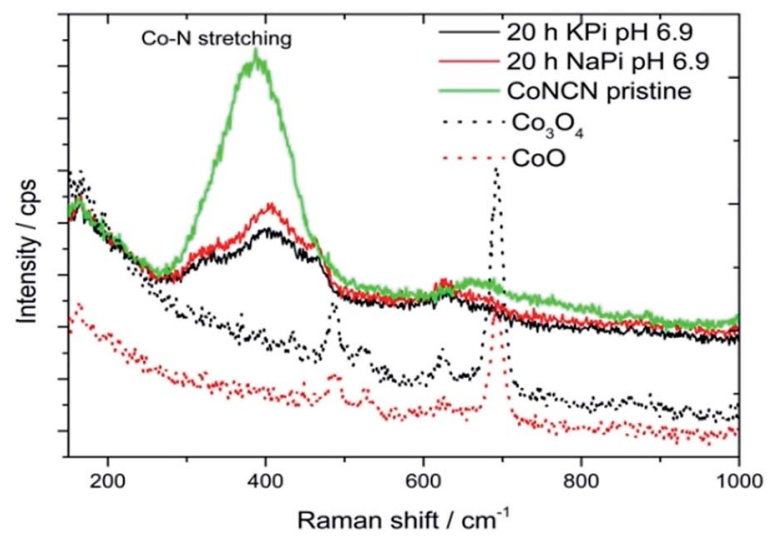

Fig. 7 Raman spectra of post-electrocatalytic CoNCN on FTO electrodes after $20 \mathrm{~h}$ of electrolysis in $\mathrm{KPi}$ and $\mathrm{NaPi}$ media $(\mathrm{pH} 7)$ vs. reference data for $\mathrm{CO}_{3} \mathrm{O}_{4}$ and $\mathrm{CoO}$. characteristic oxide vibrations and good agreement of band positions for pristine and post-electrocatalytic CoNCN. As shown in previous studies, ${ }^{34}$ the formation of significant operational amounts of cobalt oxide and CoPi films would be evident from Raman spectra. Major cobalt leaching and redeposition processes can thus be excluded. Surface analysis techniques such as XPS are not applicable in the present case, because the particles are covered with Nafion binder. Further analyses of the interplay of cobalt oxidation with the carbodiimide matrix with high-end analytical techniques are now required, beyond the scope of the present work.

\section{Transition metal tuning of carbodiimide catalysts}

We furthermore explored tuning options for the clear-cut carbodiimide matrix, starting with $\mathrm{Co} / \mathrm{Ni}$ substitution. The successful extension of the above-mentioned synthetic protocol on the formation of $\mathrm{Co}_{1-x} \mathrm{Ni}_{x} \mathrm{NCN}(x=0-1)$ solid solutions is evident from the gradual decrease of the lattice constants and from characteristic peaks in the FT-IR spectra among the series (Fig. 7 and S29-S30†). Replacement of Co with Ni leads to a sharp decrease of particle size from microscale platelets for CoNCN to nanoparticles of NiNCN with an average diameter around $21 \mathrm{~nm}$ owing to different recrystallization behavior in the salt melt (Fig. S31 $\dagger$ ). Despite an 8.5-fold higher BET surface area $\left(115 \mathrm{~m}^{2} \mathrm{~g}^{-1}\right)$ of NiNCN the main performance trends among the $\mathrm{Co}_{1-x} \mathrm{Ni}_{x} \mathrm{NCN}$ series point towards lower current densities, except for low substitution levels (LSV data in Fig. S32 $\dagger$ ). These trends are more pronounced from CV curves recorded in alkaline $0.1 \mathrm{M} \mathrm{NaOH}$ solution ( $\mathrm{pH}$ 13) shown in Fig. 8. The current density increases faster for low degrees of $\mathrm{Co}^{2+}$ substitution so that maximum performance was observed for $\mathrm{Co}_{0.9} \mathrm{Ni}_{0.1} \mathrm{NCN}$. The negligible activity of pristine NiNCN indicates that the increased activity indeed arises from CoNCN matrix tuning. However, follow-up analyses are now required to explore the combination of structural, electronic and surface 
a

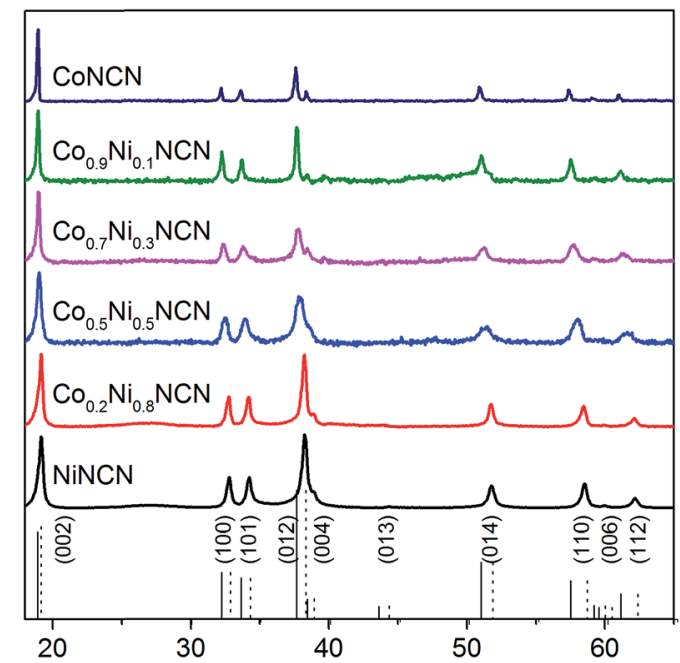

20

$2 \theta /^{\circ}$

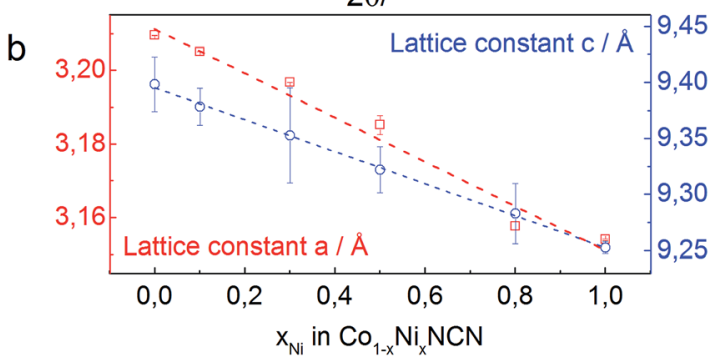

Fig. 8 (a) PXRD patterns of $\mathrm{CO}_{1-x} \mathrm{Ni}_{x} \mathrm{NCN}$ catalysts with different metal ratios and (b) the corresponding Vegard diagram (reference patterns: CoNCN [ICDD 04-015-1039] and - - - NiNCN [ICDD 04-015-1038]).

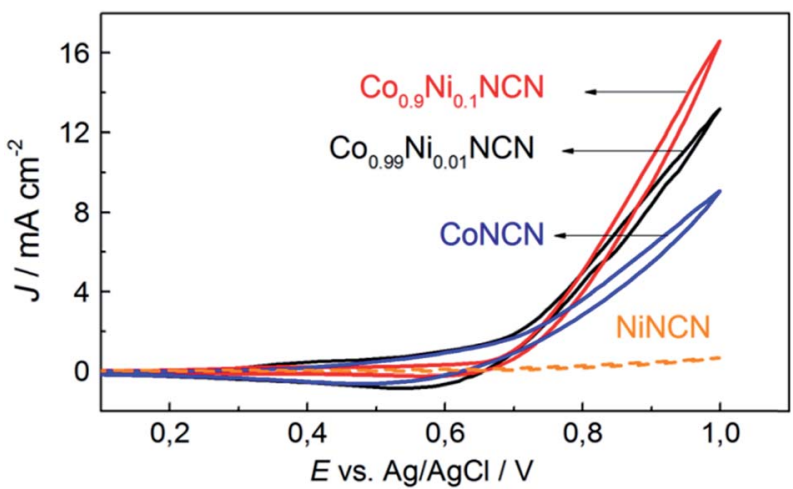

Fig. $9 \mathrm{CV}$ curves of $\mathrm{CO}_{1-x} \mathrm{Ni}_{x} \mathrm{NCN}$ catalysts with different metal ratios (glassy carbon electrodes); scan rate: $25 \mathrm{mV} \mathrm{s}^{-1}, 0.1 \mathrm{M} \mathrm{NaOH}\left(E^{0}(\mathrm{pH}\right.$ 13) $=0.27 \mathrm{~V}$ )

factors required to enhance the catalytic performance of CoNCN-based WOCs towards current benchmarks (Fig. 9).

\section{Conclusions}

Cobalt carbodiimide CoNCN emerges as a new non-oxidic water oxidation catalyst prototype with dual activity in visible-lightdriven and electrocatalytic water oxidation. CoNCN exhibits high photochemical oxygen evolution performance and outperformed appropriate reference samples of the widely used WOC $\mathrm{Co}_{3} \mathrm{O}_{4}$. This points to different catalytic reactivity patterns for metal oxides and metal carbodiimides. We thus introduce the carbodiimide matrix as a simple but versatile new system for fundamental studies of structure-activity relationships, catalytic mechanisms and surface effects.

A wide range of complementary analytical techniques clearly pointed to stability of CoNCN under photocatalytic conditions and to the absence of secondary catalytic species in solution. Bulk structural changes were excluded with PXRD, XAS and FTIR spectroscopic techniques. Furthermore, HRTEM and EDX/ EELS data did not give any indications of surface alterations. The formation of significant oxide layers during the catalytic process could be clearly excluded with XPS analyses. This sets the stage for new in situ studies into the involved active species and mechanisms, especially with respect to the possible involvement of the anions carbon or nitrogen atoms as Lewis acidic or basic centres. ${ }^{75-77}$

Moreover, CoNCN exhibits promising electrocatalytic properties, such as stability during long-term water electrolysis and an overpotential in the range of leading Co-based oxide catalysts. Major in situ transformations of CoNCN into secondary oxide electrocatalysts were excluded through XAS and Raman investigations of post-catalytic electrode materials, while cobalt leaching into the aqueous phase was ruled out with ICP-OES analyses. Advanced in-depth studies beyond the detection limits of standard analytical techniques are now required to check the new catalyst for the possible presence of subtle nanoscale heterojunctions.

Next, the tuning potential of the CoNCN host material for electrocatalytic applications was demonstrated through systematic nickel doping, and $\mathrm{Co}_{0.9} \mathrm{Ni}_{0.1} \mathrm{NCN}$ solid solutions displayed the most pronounced increase of current densities. This corresponds well with the optimal Ni-doping range for $\mathrm{Co}_{3} \mathrm{O}_{4}$ catalysts, so that design principles for other WOC types can be transferred on the novel oxide-free system. ${ }^{78}$ The carbodiimide matrix leaves room for further optimization strategies, such addressing the electrocatalytic performance with ternary metal combinations. ${ }^{79,80}$

Most importantly, CoNCN warrants novelty in structural WOC design on various levels. We present the first immobilization of abundant and powerful catalytic cobalt centers in a non-oxidic WOC matrix with the striking simplicity of the NiAs structure type. This opens up interesting alternatives to the long-standing "magic cube" design paradigm that inspired a long line of work from PSII mimics over layered oxidic WOCs to spinels, ${ }^{81}$ all of which exhibit a far more complex structural chemistry than carbodiimides. The interconnected multilayer motif of CoNCN provides excellent prerequisites for hole delocalization and rapid diffusion of active species. ${ }^{82}$ Indeed, the layered hexagonal arrangement of $\left\{\mathrm{CoN}_{6}\right\}$ octahedra was associated with higher activity than cubic $\mathrm{Co}_{3} \mathrm{O}_{4}$ under representative test conditions. Furthermore, CoNCN translates two key principles of molecular WOCs to heterogeneous catalysts, namely the embedment of Co centers into a stable nitrogencontaining environment ${ }^{83}$ along with the stabilizing effect of 
$\mathrm{N}$-Co bonds in trans position to the water binding site. ${ }^{29} \mathrm{CoNCN}$ furthermore stands out through possible new reaction patterns arising from different electronic configurations upon replacing $\mathrm{O}^{2-}$ with $\mathrm{NCN}^{2-}$, polarity effects at the catalyst-solution interface, and synergistic effects between metals and anions along with higher anionic flexibility. ${ }^{\mathbf{5 6}}$

In summary, CoNCN opens up new design avenues for combining assets of homo- and heterogeneous catalysts. CoNCN offers a straightforward and stable solid matrix with highly active and stable all-nitrogen coordination environments that can be further optimized via versatile cationic tuning. The well-defined structure of metal carbodiimide catalysts is a promising and convenient model system to obtain different theoretical and mechanistic insights into the complex multiparameter challenge of WOC construction. Dual CoNCN catalysts are a creative "melting pot" for merging non-metallic, molecular and solid state WOC features on the way to applied artificial photosynthesis.

\section{Experimental}

\section{Synthesis of $\mathrm{Co}_{1-x} \mathrm{Ni}_{x}(\mathrm{NCNH})_{2}$}

$\mathrm{Co}_{1-x} \mathrm{Ni}_{x}(\mathrm{NCNH})_{2}$ powders were synthesized by heating a mixture of anhydrous $\mathrm{CoCl}_{2} / \mathrm{NiCl}_{2}$ with the target metal ratio (130 mg, $1 \mathrm{mmol})$ with cyanamide $(1.2 \mathrm{~g}, 30 \mathrm{mmol})$ to $75^{\circ} \mathrm{C}$ in a round bottom flask under nitrogen flow. The melt was stirred until the total amounts of the metal chloride were dissolved and stirring was continued for $5 \mathrm{~min}$. $\left(\mathrm{NH}_{4}\right)_{2} \mathrm{CO}_{3}(196 \mathrm{mg}, 2 \mathrm{mmol})$ was poured into the melt to initiate the reaction by the deprotonation process, followed by $5 \mathrm{~min}$ of additional stirring. An excess of cyanamide was removed by washing with $\mathrm{H}_{2} \mathrm{O}$ prior to solidification of the melt. The precipitate was collected by centrifugation, repeatedly washed with water and dried in vacuo at $50{ }^{\circ} \mathrm{C}$ to obtain $\mathrm{Co}_{1-x} \mathrm{Ni}_{x}(\mathrm{NCNH})_{2}$ (typical yield: $91 \%$ ).

\section{Synthesis of $\mathrm{Co}_{1-x} \mathrm{Ni}_{x}(\mathrm{NCN})$}

$250 \mathrm{mg}$ of $\mathrm{Co}_{1-x} \mathrm{Ni}_{x}(\mathrm{NCNH})_{2}$ precursor powder was mixed with a LiCl-KCl eutectic salt system (6 g, 45-55 wt\%) and heated in a heating mantle to $400{ }^{\circ} \mathrm{C}$ within $20 \mathrm{~min}$. The temperature was held for $2.5 \mathrm{~h}$, followed by natural cooling of the melt to RT. The obtained salt cake was dissolved in $\mathrm{H}_{2} \mathrm{O}$ and the product was separated from the solution with a Buchner funnel and washed with $\mathrm{H}_{2} \mathrm{O}$. Drying in vacuo at $50{ }^{\circ} \mathrm{C}$ affords reddish brown (CoNCN) or yellowish (NiNCN) powders (typical yield: $92 \%$ ).

\section{Photocatalysis}

Water oxidation was performed in a $10 \mathrm{~mL}$ headspace vial sealed with an aluminum crimp cap with a rubber septum (PTFE). The reaction dispersions were prepared under dark conditions by adding the corresponding amounts of CoNCN catalysts, $\mathrm{Na}_{2} \mathrm{~S}_{2} \mathrm{O}_{8}(9.52 \mathrm{mg}, 0.04 \mathrm{mmol})$ and $\left[\mathrm{Ru}(\mathrm{bpy})_{3}\right] \mathrm{Cl}_{2}(5.12$ $\mathrm{mg}, 0.006 \mathrm{mmol}$ ) to $8 \mathrm{~mL}$ of $\mathrm{DI}_{2} \mathrm{O}$ in a glass vessel, which was subsequently sealed. The experiments were performed in different buffer solutions (0.4 M phosphate, $0.1 \mathrm{M}$ carbonate and $0.5 \mathrm{M}$ borate). The solution was degassed by purging with helium (6.0 purity) for 30 min under stirring. $\mathrm{Co}_{3} \mathrm{O}_{4}-\mathrm{NP}$ catalyst samples were synthesized according to literature protocols. ${ }^{\mathbf{1 6}}$ Commercial $\mathrm{Co}_{3} \mathrm{O}_{4}$ catalysts were purchased from Alfa Aesar and used as received.

After purging, an initial sample of the headspace $(100 \mu \mathrm{L})$ was injected into a gas chromatograph as background reference for the GC calibration. Gas chromatograms were recorded using an Agilent Technologies 7820A gas chromatograph with helium as carrier gas and a $3 \mathrm{~m} \times 2 \mathrm{~mm}$ packed molecular sieve $13 \mathrm{X} 80-$ 100 column to separate $\mathrm{O}_{2}$ and $\mathrm{N}_{2}$. The oven was operated isothermally at $80^{\circ} \mathrm{C}$. Analysis of the headspace was performed by taking $100 \mu \mathrm{L}$ samples with a Hamilton (1825 RN) gas-tight microliter syringe. Gases were detected using a thermal conductivity detector (Varian) operated at $200{ }^{\circ} \mathrm{C}$. Contamination of the headspace by air was constantly quantified by measuring the $\mathrm{N}_{2}$ peak on GC chromatograms. Calibration was performed by injection of known quantities of pure oxygen diluted in the same headspace vial containing the same volume and concentration of buffered solution as used for the measurements.

Oxygen evolution was measured both in solution using an Oxygen Sensor (OX-N) Clark electrode (Unisense). Constant temperature was maintained with a mineral insulated thermosensor ( $2 \mathrm{~mm}$ tip diameter, TP2000, Unisense). After the background calibration of the $\mathrm{GC}$, the Clark-type $\mathrm{O}_{2}$ probe was introduced through the headspace until the signal remained constant, afterwards dipped into the solution and the experiment was started after equilibrium was reached.

Signals were first calibrated using the standard procedure supplied for the applied electrode model. After complete aeration of the water ( 5 min of vigorous bubbling) in the Unisense calibration chamber CAL300, the gas stream was turned off and the saturation point for the calibration line for atmospheric partial pressure was added. Background calibration was performed with an anoxic solution prepared from sodium ascorbate and $\mathrm{NaOH}$. All experiments were conducted under controlled stirring $(500 \mathrm{rpm})$. Data collection was performed with the SensorTrace software from Unisense and a frequency of 1 data point per sec for both probes (temperature and oxygen). After a constant signal for the $\mathrm{O}_{2}$ sensor was recorded, the catalytic reaction was initiated by exposing the reaction vessel to the light of a $470 \mathrm{~nm}$ high flux LED from Rhopoint Components LTD. LED power was determined as $26.1 \mathrm{~mW} \mathrm{~cm}^{-2}$. Kinetic evaluations were performed for the initial phase of approximately linear time-dependent increase of $\mathrm{O}_{2}$ evolution $(0-60 \mathrm{~s})$ to exclude the influence of oxygen diffusion into the headspace at a later stage.

\section{Electrocatalysis}

Glassy carbon electrodes were covered with $5 \mu \mathrm{L}$ of an ultrasonicated suspension (5 mg catalyst, $350 \mu \mathrm{L}$ EtOH, $9.5 \mu \mathrm{L}$ Nafion $\left(20 \%\right.$ in $\left.\left.\mathrm{H}_{2} \mathrm{O}\right)\right)$ and FTO glass electrodes $(\sim 1 \times 1.5 \mathrm{~cm})$ with $20 \mu \mathrm{L}$ of an ultrasonicated suspension (5 mg catalyst, $700 \mu \mathrm{L}$ EtOH, $19 \mu \mathrm{L}$ Nafion (20\% in $\left.\mathrm{H}_{2} \mathrm{O}\right)$ ). Electrochemical measurements were carried out with a Gamry Instruments potentiostat 600 and evaluated with the Gamry EIS 300/Physical Electrochemistry software. The experiments were performed in 
a standard three-electrode setup (sat. $\mathrm{Ag} / \mathrm{AgCl}$ reference electrode (Ag/AgCl vs. NHE: $+197 \mathrm{mV})$, platinum wire counter electrode) in $0.1 \mathrm{M}$ of phosphate $(\mathrm{pH} 7)$ or $\mathrm{KOH}(\mathrm{pH} 13.1)$ buffer solutions. CV cycles were recorded with a scan rate of $25 \mathrm{mV} \mathrm{s}^{-1}$ and LSV curves with a scan rate of 10,5 or $1 \mathrm{mV} \mathrm{s}^{-1}$ at an electrode rotation speed of $1500 \mathrm{rpm}$. Chronoamperometry scans were performed with an equilibrium time of $60 \mathrm{~s}$ at a given potential. The double layer capacitance of CoNCN was determined from cycling at different scan rates in the nonFaradaic region in a potential window of $0.1 \mathrm{~V}$ (from $0.0 \mathrm{~V}$ to $0.1 \mathrm{~V}$ vs $\mathrm{Ag} / \mathrm{AgCl})$. The working electrode was held at each potential for $10 \mathrm{~s}$ before the measurement. The electrochemical double layer capacitance $C_{\mathrm{DL}}$ was determined by applying $i_{\mathrm{c}}=v C_{\mathrm{DL}}$, where $v$ is the scan rate and $i_{\mathrm{c}}$ the current density at $0.05 \mathrm{mV}$.

\section{Analytical characterization}

Powder X-ray diffraction patterns (PXRD) were collected in reflection mode on a Bruker D8 device, equipped with a Kevex fluorescence shield detector ( $\mathrm{Cu} \mathrm{K} \mathrm{K}_{\alpha}$ radiation). The Scherrer equation was applied with a form factor of $K=0.9$. Scanning electron microscopy (SEM) images were recorded with a JEOL JSM-7500 F instrument. Fourier transform infrared spectroscopy (FT-IR) spectra were collected on a Thermo Scientific Nicolet iS5 spectrometer in ATR mode with a resolution of $4 \mathrm{~cm}^{-1}$. Elemental analysis for nitrogen and carbon was performed with an Elementarvario MICRO cube. Nitrogen sorption isotherms were recorded after degassing at $80{ }^{\circ} \mathrm{C}$ for $20 \mathrm{~h}$ by using a Quantachrome Quadrasorb SI porosimeter at $77 \mathrm{~K}$. Absorption branch points $\left(0.1>p / p^{0}<0.3\right)$ were applied in the BET model to calculate the apparent surface area. Transmission electron microscopy (TEM) and energy-dispersive X-ray spectroscopy (EDX) analyses were performed on a Philips CM200FEG microscope (200 kV, field emission gun). UV/vis absorbance spectra were recorded on a Varian spectrophotometer equipped with an optical integrating sphere. ICP-OES was measured on a Varian Vista-MPX instrument equipped with a CCD detector. Aqueous calibration solutions of 5, 20 and 50 ppm were freshly prepared from Merck millipore standard solutions (1000 ppm).

Cobalt K-edge X-ray absorption spectroscopy was performed at the ESRF Swiss Norwegian Beamline BM01B in transmission mode. CoNCN was measured as solid samples dispersed in cellulose. $\mathrm{CoO}, \mathrm{Co}_{3} \mathrm{O}_{4}$ and $\mathrm{LiCoO}_{2}$ were used as reference samples for cobalt valence determination. Due to the low concentration of cobalt post-catalytic FTO electrodes were measured in fluorescence mode using the vortex fluorescence detector. Cobalt metal foil was used as calibration standard for all experiments. Energy calibration, background removal and Fourier transformation of XAS spectra were performed with the Athena software and EXAFS fits were performed with the Artemis software. ${ }^{\mathbf{8 4}}$ Raman spectra were recorded on a Remishaw Ramascope spectrometer equipped with diode laser (785 nm). XPS spectra were recorded with a Quantum 2000 spectrometer from Physical Electronics Inc. using monochromatized $\mathrm{Al} \mathrm{K}_{\alpha}$ radiation and an electron as well as an ion neutralizer. The samples were measured as prepared, i.e. no sputter cleaning was performed. No peak shifting (energy scale calibration) was performed.

\section{Acknowledgements}

Financial support by the Swiss National Science Foundation (Sinergia Grant no. CRSII2_136205/1), by the University of Zurich (UFSP LightChEC: F. E., R. M. and G. R. P.), and by the Max Planck Society (D. R., M. S. and M. A.) is gratefully acknowledged. We thank Dr Guylhaine Clavel (Fritz Haber Institute) for HRTEM and EELS analyses. We thank Dr Paula Abdala and Dr Herman Emerich (ESRF Grenoble) for beamline support and Adrià Garcia Gil (UZH) for experimental assistance.

\section{Notes and references}

1 T. R. Cook, D. K. Dogutan, S. Y. Reece, Y. Surendranath, T. S. Teets and D. G. Nocera, Chem. Rev., 2010, 110, 64746502.

2 N. S. Lewis and D. G. Nocera, Proc. Natl. Acad. Sci. U. S. A., 2006, 43, 15729-15735.

3 S. Berardi, S. Drouet, L. Francàs, C. Gimbert-Surinach, M. Guttentag, C. Richmond, T. Stoll and A. Llobet, Chem. Soc. Rev., 2014, 43, 7501-7519.

4 J. R. Swierk and T. E. Mallouk, Chem. Soc. Rev., 2013, 42, 2357-2387.

5 L. Alibabaei, M. K. Brennaman, M. R. Norris, B. Kalanyan, W. Song, M. D. Losego, J. J. Concepcion, R. A. Binstead, G. N. Parsons and T. J. Meyer, Proc. Natl. Acad. Sci. U. S. A., 2013, 110, 20008-20013.

6 S. Styring, Faraday Discuss., 2012, 155, 357-376.

7 Y. Tachibana, L. Vayssieres and J. Durrant, Nat. Photonics, 2012, 6, 511-518.

8 F. Osterloh, Chem. Soc. Rev., 2013, 42, 2294-2320.

9 K. J. Young, L. A. Martini, R. L. Milot, R. C. Snoeberger, V. S. Batista, C. A. Schmuttenmaer, R. H. Crabtree and G. W. Brudvig, Coord. Chem. Rev., 2012, 256, 2503-2520.

10 A. Singh and L. Spiccia, Coord. Chem. Rev., 2013, 257, 26072622.

11 A. Sartorel, M. Bonchio, S. Campagna and F. Scandola, Chem. Soc. Rev., 2013, 42, 2262-2280.

12 J. G. McAlpin, T. A. Stich, W. H. Casey and R. D. Britt, Coord. Chem. Rev., 2012, 256, 2445-2452.

13 I. McConnell, G. Li and G. W. Brudvig, Chem. Biol., 2010, 17, 434-447.

14 N. Cox, D. A. Pantazis, F. Neese and W. Lubitz, Acc. Chem. Res., 2013, 46, 1588-1596.

15 A. Minguzzi, O. Lugaresi, E. Achilli, C. Locatelli, A. Vertova, P. Ghigna and S. Rondini, Chem. Sci., 2014, 5, 3591-3597.

16 S. P. Phivilay, A. P. Puretzky, K. Domen and I. E. Wachs, ACS Catal., 2013, 3, 2920-2929.

17 M. Matsukawa, R. Ishikawa, T. Hisatomi, Y. Moriya, N. Shibata, J. Kubota, Y. Ikuhara and K. Domen, Nano Lett., 2014, 14, 1038-1041.

18 M. M. Waegele, X. Chen, D. M. Herlihy and T. Cuk, J. Am. Chem. Soc., 2014, 136, 10632-10639. 
19 H. Han and H. Frei, J. Phys. Chem. C, 2008, 112, 1615616159.

20 M. W. Kanan, J. Yano, Y. Surendranath, M. Dinca, V. K. Yachandra and D. G. Nocera, J. Am. Chem. Soc., 2010, 132, 13692-13701.

21 H. G. Sanchez Casalongue, M. L. Ng, S. Kaya, D. Friebel, H. Ogasawara and A. Nilsson, Angew. Chem., Int. Ed., 2014, 126, 7297-7300.

22 Y. Gorlin, B. Lassalle-Kaiser, J. D. Benck, S. Gul, S. M. Webb, V. K. Yachandra, J. Yano and T. F. Jaramillo, J. Am. Chem. Soc., 2013, 135, 8525-8534.

23 M. Risch, A. Grimaud, K. J. May, K. A. Stoerzinger, T. J. Chen, A. N. Mansour and Y. Shao-Horn, J. Phys. Chem. C, 2013, 117, 8628-8635.

24 J. R. Swierk and T. E. Mallouk, Chem. Soc. Rev., 2013, 42, 2357-2387.

25 C. Zuccaccia, G. Bellachioma, O. Bortolini, A. Bucci, A. Savini and A. Macchioni, Chem.-Eur. J., 2014, 20, 3446-3456.

26 M. Grzelczak, J. Zhang, J. Pfrommer, J. Hartmann, M. Driess, M. Antonietti and X. Wang, ACS Catal., 2013, 3, 383-388.

27 B. Klahr and T. Hamann, J. Phys. Chem. C, 2014, 118, 1039310399.

28 J. M. Thomsen, S. W. Sheehan, S. M. Hashmi, J. Campos, U. Hintermair, R. H. Crabtree and G. W. Brudvig, J. Am. Chem. Soc., 2014, 136, 13826-13843.

29 V. Artero, M. Chavarot-Kerlidou and M. Fontecave, Angew. Chem., Int. Ed., 2011, 50, 7238-7266.

30 J. B. Gerken, J. G. McAlpin, J. Y. C. Chen, M. L. Rigsby, W. H. Casey, R. D. Britt and S. S. Stahl, J. Am. Chem. Soc., 2011, 133, 14431-14442.

31 X. Deng and H. Tüysüz, ACS Catal., 2014, 4, 3701-3714.

32 J. J. Stracke and R. G. Finke, ACS Catal., 2014, 4, 79-89.

33 J. W. Vickers, H. Lv, J. M. Sumliner, G. Zhu, Z. Luo, D. G. Musaev, Y. V. Geletii and C. L. Hill, J. Am. Chem. Soc., 2013, 135, 14110-14118.

34 H. S. Ahn and T. D. Tilley, Adv. Funct. Mater., 2013, 23, 227233.

35 A. Harriman, I. J. Pickering and J. M. Thomas, J. Chem. Soc., Faraday Trans., 1988, 84, 2795-2806.

36 D. Shevchenko, M. F. Anderlund, A. Thapper and S. Styring, Energy Environ. Sci., 2011, 4, 1284-1287.

37 M. Zhang, M. de Respinis and H. Frei, Nat. Chem., 2014, 6, 362-367.

38 M. W. Kanan, Y. Surendranath and D. G. Nocera, Chem. Soc. Rev., 2009, 38, 109-114.

39 R. D. L. Smith, M. S. Prévot, R. D. Fagan, Z. Zhang, P. A. Sedach, M. K. J. Siu, S. Trudel and C. P. Berlinguette, Science, 2013, 340, 60-63.

40 H. Dau, C. Limberg, T. Reier, M. Risch, S. Roggan and P. Strasser, ChemCatChem, 2010, 2, 724-761.

41 Y. Liu and D. G. Nocera, J. Phys. Chem. C, 2014, 118, 1706017066.

42 Y. Surendranath, M. W. Kanan and D. G. Nocera, J. Am. Chem. Soc., 2010, 132, 16501-16509.

43 X. L. Hu, S. Piccinin, A. Laio and S. Fabris, ACS Nano, 2012, 12, 10497-10504.
44 M. Risch, K. Klingan, F. Ringleb, P. Chernev, I. Zaharieva, A. Fischer and H. Dau, ChemSusChem, 2012, 5, 542-549.

45 M. Richter and D. Schmeißer, Appl. Phys. Lett., 2013, 102, 253904.

46 K. Maeda and K. Domen, J. Phys. Chem. C, 2007, 111, 78517861.

47 Y.-R. Zheng, M.-R. Gao, Q. Gao, H.-H. Li, J. Xu, Z.-Y. Wu and S.-H. Yu, Small, 2015, 11, 182-188.

48 Y. Zheng, Y. Jiao, Y. Zhu, L. H. Li, Y. Han, Y. Chen, A. Du, M. Jaroniec and S. Z. Qiao, Nat. Commun., 2014, 5, 3783.

49 M. Shalom, S. Gimenez, F. Schipper, I. Herraiz-Cardona, J. Bisquert and M. Antonietti, Angew. Chem., Int. Ed., 2014, 53, 3654-3658.

50 T.-P. Fellinger, F. Hasché, P. Strasser and M. Antonietti, J. Am. Chem. Soc., 2012, 134, 4072-4075.

51 X. Wang, K. Maeda, A. Thomas, K. Takanabe, G. Xin, J. M. Carlsson, K. Domen and M. Antonietti, Nat. Mater., 2009, 8, 76-80.

52 B. Kumar, M. Asadi, D. Pisasale, S. Sinha-Ray, B. A. Rosen, R. Haasch, J. Abiade, A. L. Yarin and A. Salehi-Khojin, Nat. Commun., 2013, 4, 2819.

53 Y. Zhao, R. Nakamura, K. Kamiya, S. Nakanishi and K. Hashimoto, Nat. Commun., 2013, 4, 1-7.

54 A. B. Jorge, D. J. Martin, M. T. S. Dhanoa, A. S. Rahman, N. Makwana, J. Tang, A. Sella, F. Cora, S. Firth, J. A. Darr and P. F. McMillan, J. Phys. Chem. C, 2013, 117, 7178-7185.

55 P. Chen, L.-K. Wang, G. Wang, M.-R. Gao, J. Ge, W.-J. Yuan, Y.-H. Shen, A.-J. Xie and S.-H. Yu, Energy Environ. Sci., 2014, 7, 4095-4103.

56 J. Duan, S. Chen, S. Dai and S. Z. Qiao, Adv. Funct. Mater., 2014, 24, 2072-2078.

57 J. Zhu, A. Holmen and D. Chen, ChemCatChem, 2013, 5, 378401.

58 Y. Wang, J. Yao, H. Li, D. Su and M. Antonietti, J. Am. Chem. Soc., 2011, 133, 2362-2365.

59 M. L. Toebes, T. Alexander Nijhuis, J. Hájek, J. H. Bitter, A. Jos van Dillen, D. Y. Murzin and K. P. de Jong, Chem. Eng. Sci., 2005, 60, 5682-5695.

60 W. Zhao, Y. Liu, J. Liu, P. Chen, I.-W. Chen, F. Huang and J. Lin, J. Mater. Chem. A, 2013, 27, 7942-7948.

61 S. Pintado, S. Goberna-Ferrón, E. C. Escudero-Adán and J. R. Galán-Mascarós, J. Am. Chem. Soc., 2013, 36, 1327013273.

62 S. Goberna-Ferrón, W. Y. Hernández, B. Rodríguez-García and J. R. Galán-Mascarós, ACS Catal., 2014, 4, 1637-1641.

63 J. Masa, W. Xia, I. Sinev, A. Zhao, Z. Sun, S. Grützke, P. Weide, M. Muhler and W. Schuhmann, Angew. Chem., Int. Ed., 2014, 53, 8508-8512.

64 J. Pfrommer, M. Lublow, A. Azarpira, C. Göbel, M. Lücke, A. Steigert, M. Pogrezeba, P. W. Menezes, A. Fischer, T. Schnedel-Niedrig and M. Driess, Angew. Chem., Int. Ed., 2014, 53, 5183-5187.

65 A. J. Bloomfield, S. W. Sheehan, S. L. Collom, R. H. Crabtree and P. T. Anastas, New J. Chem., 2014, 38, 1540-1545.

66 M. Krott, X. Liu, B. P. T. Fokwa, M. Speldrich, H. Lueken and R. Dronskowski, Inorg. Chem., 2007, 46, 2204-2207. 
67 F. Evangelisti, R. Güttinger, R. Moré, S. Luber and G. R. Patzke, J. Am. Chem. Soc., 2013, 50, 18734-18737.

68 M. Hara, C. C. Warasaka, J. T. Lean, B. A. Lewis and T. E. Mallouk, J. Phys. Chem. A, 2000, 104, 5275-5280.

69 H. Lv, J. A. Rudd, P. F. Zhuk, J. Y. Lee, E. C. Constable, C. E. Housecroft, C. L. Hill, D. G. Musaev and Y. V. Geletii, RSC Adv., 2013, 3, 20647-20654.

70 H. Liu and G. R. Patzke, Chem.-Asian J., 2014, 9, 2249-2259.

71 S. C. Petitto, E. M. Marsh, G. A. Carson and M. A. Langell, J. Mol. Catal. A: Chem., 2008, 281, 49-58.

72 M. C. Biesinger, B. P. Payne, A. P. Grosvenor, L. W. M. Lau, A. R. Gerson and R. St. C. Smart, Appl. Surf. Sci., 2011, 257, 2717-2730.

73 R. H. Crabtree, Chem. Rev., 2012, 112, 1536-1554.

74 Y. Surendranath, M. W. Kanan and D. G. Nocera, J. Am. Chem. Soc., 2010, 132, 16501-16509.

75 R. A. Sidik, A. B. Anderson, N. P. Subramanian, S. P. Kumaraguru and B. N. Popov, J. Phys. Chem. B, 2006, 110, 1787-1793.
76 Y. Zhao, R. Nakamura, K. Kamiya, S. Nakanishi and K. Hashimoto, Nat. Commun., 2013, 4, 2390.

77 B. Kumar, M. Asadi, D. Pisasale, S. Sinha-Ray, B. A. Rosen, R. Haasch, J. Abiade, A. L. Yarin and A. Salehi-Khojin, Nat. Commun., 2013, 4, 2819.

78 X. Zou, J. Su, R. Silva, A. Goswami, B. R. Sathe and T. Asefa, Chem. Commun., 2013, 49, 7522-7524.

79 R. D. L. Smith, M. S. Prévot, R. D. Fagan, S. Trudel and C. P. Berlinguette, J. Am. Chem. Soc., 2013, 135, 11580-11586. 80 X. Liu, L. Stork, M. Speldrich, H. Lueken and R. Dronskowski, Chem.-Eur. J., 2009, 15, 1558-1561.

81 G. P. Gardner, Y. B. Go, D. M. Robinson, P. F. Smith, J. Hadermann, A. Abakumov, M. Greenblatt and G. C. Dismukes, Angew. Chem., Int. Ed., 2012, 51, 1616-1619. 82 C. L. Farrow, D. K. Bediako, Y. Surendranath, D. G. Nocera and S. J. L. Billinge, J. Am. Chem. Soc., 2013, 135, 6403-6406.

83 D. J. Wasylenko, C. Ganesamoorthy, J. Borau-Garcia and C. P. Berlinguette, Chem. Commun., 2011, 47, 4249-4251.

84 B. Ravel and M. Newville, J. Synchrotron Radiat., 2005, 12, 537-541. 